\title{
The debut of The Journal of Headache and Pain
}

The debut of a new scientific journal is an important and complex event, representing the onset of a journey full of hurdles, but with an exciting goal: to give one more possibility, another "court", to diffuse and debate scientific knowledge. Research should be free in all its phases, from working hypotheses to the conclusive results and their divulgation.

A few colleagues did not share this enthusiasm for the birth of a new journal, on the grounds that two other journals devoted to headache already exist. We would like to stress that our intention is not to put The Journal of Headache and Pain in contrast to the already existing, prestigious journals. We would rather promote and strengthen the scientific production on these topics throughout the world, with special attention to the many nations where headache and pain centres are still few.

One of our major tasks is to promote knowledge and to favour cultural and scientific discussion. To this purpose, we remember the members' meeting of the International Headache Society (IHS), held in Barcelona in June 1999. The audience consisted of eleven people, of whom six were Italian. This implies that participation in this important IHS event leaves members with a feeling of discomfort and "disengagement". Another reason may be the language. We must encourage the use of English, helping anyone who is able to contribute to the scientific debate but does not have yet a fluent knowledge of it. Language must not be a barrier and must not be used as a subtle instrument of exclusion.

The Journal of Headache and Pain will focus attention on headache and the wider chapter of pain, thus rediscovering the robust Italian tradition on this topic. The first Chair of Physiopathology and Pain Treatment in the world was established at the University of Milan in 1982 and held by Professor Mario Tiengo. Pain, as Cartesius wrote, is a warning system which alerts the soul of a forthcoming danger. In this sense, it has a positive effect but leaves us with a problem of the pain we have to defeat. In the field of headache, Italian researchers are the authors of more than $15 \%$ of the scientific production indexed in Medline over the last decade.

Since its foundation in Florence in 1976, the Italian Society for the Study of Headaches (SISC) has created two journals: Hemicrania and Confinia Cephalalgica. In Italy, medical researchers from various disciplines ranging from basic sciences to neurology, internal medicine, clinical pharmacology, childhood and adolescent neuropsychiatry, rheumatology, anaesthetics, and emergency medicine, as well as general practitioners, have been studying pain and headache over a long period of time. Now other dis- 
ciplines are turning their interest and considerable enthusiasm to this theme. For this reason, SISC has promoted a new journal to be used as an instrument in the challenge to pain. We are certain that, in the third millennium, there will be a strong impulse to research, particularly in emerging countries. Thus, there will be an increasing need for means in which to communicate and grow in the scientific field and to exchange scientific points of view: The Journal of Headache and Pain offers an additional opportunity for publishing. The submission of a paper to our journal should, in any case, be useful to the researcher, regardless of whether it is published or not. For this reason, reviews of the articles will remain strictly anonymous and will be carried out by three referees competent in the topic in question. Their aim will be to guarantee the quality of the papers and to supply the authors with detailed, constructive information.

We would like to begin a new cultural season in which existing journals will continue to grow and, contemporarily, new realities to promote this growth will be established. How can one think that this new season will "blossom" only in the present scenario and that one-way globalisation, which refuses weaker realities, can be the answer? For the progress of the new journal, we ask the support of established colleagues and of younger researchers who wish to emerge, par- ticularly in the less represented research fields.

The structure of the journal will include editorials, review articles, and original papers; a space will be reserved for comments (on invitation), brief reports and letters. We will pay particular attention to rapid communications, which will allow us to publish quickly, and almost in real time, findings of fundamental scientific importance. Another space, dedicated to controversies ("Pros and Cons"), will permit a direct debate between researchers on fundamental subjects which are object of discussion. Each issue will close with congress announcements and scientific news. Moreover, the journal will be fully accessible through the Springer LINK Information Service at http://link.springer.de/link/ service/journals/10194/ (User-ID, head2000; Password, sisc).

We would like to express our warmest thanks to Springer-Verlag for having accepted to be our publisher. Particular thanks go to Professor Moskowitz, Professor Saxena and to all the foreign and Italian colleagues of the Advisory Board, for having accepted the challenge of our new journal and for having given their tangible contribution towards freedom of thought.

The moment has arrived to let our "kite" soar high up in the blue sky, becoming visible to everybody who would like to join us in this scientific adventure.

Francomichele Puca Gennaro Bussone Paolo Martelletti Virgilio Gallai
Founding Editors

